\title{
Author Correction: Radiotherapy toxicity
}

Dirk De Ruysscher, Gabriele Niedermann, Neil G. Burnet, Shankar Siva,

Anne W. M. Lee and Fiona Hegi-Johnson

Nature Reviews Disease Primers (2019) https://doi.org/10.1038/s41572-019-0064-5

Published online 21 February 2019

In the version originally published, an incorrect version of Figure 1 was used. This has now been replaced.

https://doi.org/10.1038/s41572-019-0073-4 I Published online: 04 March 2019 